\title{
Um Estudo sobre a Eficácia dos Recursos Interativos do Ambiente Moodle no curso de Licenciatura em Informática na Modalidade a Distância
}

\author{
Elizangela Tonelli*1, João Paulo de Brito Gonçalves², Raiza Teixeira Griffo \\ Vasconcelos ${ }^{3}$
}

\footnotetext{
1 Professor, Coordenadoria de Matemática/Instituto Federal do Espírito Santo Fazenda Morro Grande Cachoeiro de Itapemirim - ES - Brasil. elizangelat@ifes.edu.br

2 Professor, Coordenadoria de Informática/Instituto Federal do Espírito Santo Fazenda Morro Grande Cachoeiro de Itapemirim - ES - Brasil. jpaulo@ifes.edu.br

3 Pesquisador, Coordenadoria de Licenciatura em Informática/Instituto Federal do Espírito Santo Fazenda Morro Grande - Cachoeiro de Itapemirim - ES - Brasil. raizav@ifes.edu.br
}

\section{Resumo}

A educação a distância é considerada uma forma de aprendizagem que possibilita o autoconhecimento, fazendo uso de uma mediação sistemática com recursos de ensino, apresentados em diferentes mídias. Este estudo visa analisar a efetividade dos recursos interativos do Moodle através da percepção de alunos do curso de Licenciatura em Informática a Distância acerca das ferramentas síncronas e assíncronas usadas. Para atingir o objetivo proposto, foi conduzida uma pesquisa descritiva e exploratória com uma abordagem de análise qualitativa com 16 estudantes e 22 professores e pesquisa nas fontes de literatura existentes sobre o assunto. A videoaula foi vista como uma ferramenta muito efetiva para entender o conteúdo, considerando que está disponível no AVA, o estudante pode assisti-la quantas vezes ele quiser.

Palavras-chave: Educação a distância, Ambiente de aprendizagem interativo, Aprendizagem significativa. 


\title{
A Study on the Interactive Features Effectiveness in Moodle Environment in Informatics Degree Distance Course
}

\begin{abstract}
Distance Education is considered a way of teaching that enables self-learning, making use of a systematic mediation with teaching resources, presented in different media. This study aims to analyze the interactive features effectiveness of Moodle according to the Informatics degree distance students' perceptions about synchronous and asynchronous used tools. In order to achieve the proposed objective, we carried out a descriptive and exploratory research with quantitative analysis approach, with 16 students and 22 professors, and research on existing literature sources about the subject. The video lesson was seen as a very effective tool for understanding the content, since it is available on VLE, student $s$ can watch it as many times as they wants.
\end{abstract}

Keywords: Distance education, Virtual learning environment, Meaningful learning. 


\section{Introdução}

A Educação a Distância no Brasil, nos termos da Lei de Diretrizes e Bases (LDB), é considerada como uma forma de ensino que possibilita a autoaprendizagem, fazendo uso de uma mediação sistematizada de recursos didáticos, apresentados em diferentes meios de informação, que são utilizados separadamente ou combinados.

Ausubel (1978) diz que o indivíduo aprende a partir do momento em que ele consegue fazer a conexão entre o novo conteúdo com um conhecimento prévio já existente em sua estrutura cognitiva, ou seja, quando a aprendizagem é significativa. Conforme destaca Machado e Santos (2004), o ambiente virtual criado na plataforma Moodle permite ao estudante estabelecer diversas associações entre os assuntos interrelacionados, o que favorece a ampliação de sua visão sobre um determinado tema de estudo, sua capacidade de associar ideias e a integração de novos conceitos em sua estrutura cognitiva.

Ainda existem muitas dúvidas em relação à função do licenciado em informática, já que é um perfil de profissional novo no mercado. Uma das visões é que este seria um profissional capacitado para o uso das mais variadas ferramentas tecnológicas que auxiliariam no processo de ensino-aprendizagem através de softwares educacionais ou de utilitários; outra é de que o professor licenciado em informática é um técnico em informática com a função de administrar o laboratório prestando assistência técnica aos computadores e equipamentos.

De acordo com o currículo referência desenvolvido pela Sociedade Brasileira de Computação (2002), espera-se que o aluno egresso do curso de licenciatura em informática seja um profissional com competências e habilidades desenvolvidas durante o curso que Ihe permitam:

- Compreender processos educativos e de aprendizagem de forma a estabelecer relações entre informática e educação;

- Atuar como agente de processos e vivências educativas em computação, articulando os conteúdos com as didáticas específicas, na busca de solução de problemas da sociedade humana;

- Promover a aprendizagem criativa, autônoma, colaborativa e de comunicação e expressão; 
- Contribuir para a aprendizagem empreendedora, na perspectiva de valorização dos indivíduos, de suas capacidades, de suas relações sociais e éticas num processo de transformação de si próprio e de seu espaço social.

A SBC (2002) descreve os conteúdos formativos do perfil dos profissionais licenciados em informática, os quais possuem embasamento tanto tecnológico com os conceitos da ciência da computação quanto pedagógico através da formação sociológica e filosófica.

Dessa forma, o principal objetivo deste trabalho foi analisar o quanto as ferramentas do ambiente Moodle propiciam a aprendizagem significativa dos alunos e o quanto elas são usadas para comunicação entre os diversos atores do processo.

\section{Metodologia}

Fez-se um estudo de caso adotando-se uma abordagem descritiva/comparativa e de caráter quanti-qualitativo. De acordo com Minayo e Sanches (1993), a pesquisa qualitativa e a pesquisa quantitativa são formas de se aproximar da realidade e podem e devem ser utilizadas como complementares, pois, dessa forma, um estudo quantitativo possibilita gerar questões que podem ser aprofundadas qualitativamente e vice-versa.

Para Silva e outros autores (2008), quando se tem como foco a pesquisa em Educação é preciso que se considere o caráter quantitativo e o qualitativo, pois dessa forma teremos concepções distintas do pensamento humano.

Sendo assim a opção deve-se ao fato de que a complementação qualitativa auxilia na apreensão de outros significados presentes, que não podem ser apenas quantificados no contexto investigado, permitindo ao pesquisador acesso a informações relevantes, para um melhor entendimento do objeto em estudo.

\subsection{Contexto do Estudo}

A pesquisa foi realizada no Estado do Espírito Santo, no curso de graduação Licenciatura em Informática, ofertado pelo Instituto Federal do Espírito Santo - IFES, 
na modalidade EaD. O curso iniciou o seu processo de implantação em 2006 pelo CEFET/ES, hoje IFES, em parceria com a Universidade Aberta do Brasil - UAB.

\subsection{Participantes do Estudo}

O curso teve início no $2^{\circ}$ semestre de 2009 com 35 alunos matriculados no polo de Cachoeiro de Itapemirim. Na ocasião da aplicação dos questionários, em janeiro de 2013, esse número baixou para 16 alunos.

Sendo assim, para este estudo a amostra contou com 38 sujeitos: 16 alunos e 22 professores formadores, distribuídos da seguinte forma:

- Dezesseis alunos cursando o $8^{\circ}$ período;

- Quatro tutores presenciais;

- Oito tutores a distância envolvendo as áreas tecnológicas e pedagógicas;

- Dez professores especialistas.

\subsection{Coleta de Dados}

Como instrumento para coleta dos dados, optou-se pela utilização de um único questionário para os professores formadores com 40 perguntas e um único questionário para os alunos com 37 perguntas. Ambos continham questões semelhantes com perguntas objetivas e subjetivas, relacionadas às questõesproblemas, com o intuito de comparar a opinião de alunos e professores que direcionassem para a ocorrência ou não da aprendizagem significativa na EaD conforme propõe a teoria de David Ausubel.

Os questionários foram preparados utilizando o Google Docs e o link foi enviado para os professores conteudistas/especialistas, tutores a distância e tutores presenciais por e-mail. A escolha da forma de envio deve-se ao fato de que a maioria dos professores residem em municípios distintos no Espírito Santo. Os questionários foram aplicados entre os dias 08 de abril a 30 de maio de 2013. O primeiro envio foi feito no dia 08 de abril de 2013 e obteve, em média, 70\% das respostas. Após 40 dias, foi feito o reenvio dos mesmos, ressaltando aos sujeitos a importância da pesquisa e foram obtidos $100 \%$ de êxito nas respostas. 


\subsection{Análise dos Dados}

A aplicação dos questionários aos alunos foi feita no polo de apoio presencial, no dia 4 de maio de 2013. Após uma breve fala sobre a importância da pesquisa bem como dos objetivos da mesma, o questionário foi aplicado. A média de tempo para respondê-lo foi de aproximadamente 40 minutos. O retorno dos questionários foi de $100 \%$.

Os questionários elaborados foram divididos em duas partes: a primeira teve o intuito de traçar as características pessoais do sujeito/respondente e de sua atuação no Ensino a Distância conforme descrito anteriormente; a segunda parte referiu-se à prática docente e discente em relação a fatores que contribuem ou não para ocorrência da aprendizagem significativa na modalidade a distância.

A segunda parte do questionário do professor e do aluno abordou questões relacionadas à ocorrência da aprendizagem significativa.

Para este trabalho, foi escolhida a primeira parte do questionário referente às ferramentas Interativas do ambiente Moodle e se elas propiciam a aprendizagem significativa.

As ferramentas avaliadas foram:

- Fórum - a função dos fóruns na plataforma Moodle é permitir a comunicação entre professores e alunos através de debates entre os participantes. A forma de comunicação é assíncrona, ou seja, as pessoas não precisam estar conectadas simultaneamente para contribuir dando suas opiniões. Os fóruns permitem ainda que várias pessoas acompanhem as discussões sobre um determinado tópico.

- Videoaula - é uma forma efetiva de disponibilizar conteúdo por meio da imagem do professor que grava uma aula e esta fica disponível no ambiente para que os alunos a assistam quando quiserem.

- Webconferência - é uma ferramenta que permite a interação entre professor e aluno de forma síncrona, onde o professor exibe sua imagem e pode disponibilizar apresentações e vídeos enquanto os alunos interagem em um ambiente de aula simulado, podendo pedir a palavra e fazer perguntas tanto por texto quanto por áudio. 
- Chat - é uma ferramenta síncrona que implica em um canal de conversação geralmente no modo texto entre professor e aluno.

- Correio Eletrônico - é uma forma de comunicação assíncrona que simula a comunicação via correio, onde existe um remetente e um destinatário para a mensagem.

\section{Resultados e discussão}

Conforme referenciado anteriormente, o ambiente virtual oferece uma ferramenta para a aprendizagem significativa. Avaliou-se, então, a eficácia das ferramentas disponibilizadas no AVA do curso em estudo, como facilitadoras na compreensão dos conteúdos numa escala contínua de "ineficaz" a "muito eficaz". Entre as avaliações feitas pelos alunos, no que diz respeito à compreensão dos conteúdos, somando as porcentagens das notas 4 (eficaz) e 5 (muito eficaz), a videoaula obteve $81 \%$; o fórum com $75 \%$; o e-mail obteve $68 \%$; a webconferência com $62 \%$; e o chat com $50 \%$ conforme mostra a Tabela 1 .

Tabela 1: Avaliação dos alunos sobre os recursos interativos e visuais do AVA.

\begin{tabular}{l}
$\begin{array}{l}\text { FERRAMENTAS DO } \\
\text { AVA }\end{array}$ \\
\cline { 2 - 14 }
\end{tabular}

Como uma das questões discursivas do questionário, solicitou-se aos alunos que justificassem a avaliação feita para a ferramenta considerada menos eficaz: o chat. Apesar de ser considerada uma ferramenta de contato imediato com o tutor a distância, por ser síncrona, foi apontado como menos eficaz devido à pouca 
participação dos alunos por conta da incompatibilidade de horário com o dos professores. Como muito eficaz, foi indicada a videoaula. Como uma das questões discursivas do questionário, pediu-se que justificassem a escolha. Os alunos relataram que, por meio dessa ferramenta, é possível ter uma explicação mais detalhada dos conteúdos considerados mais complexos e por ela simular uma sala de aula. O fórum também foi mencionado como "muito eficaz" por ser uma ferramenta de rápida interação e clareza nos assuntos abordados. Além disso, a webconferência também teve destaque na avaliação dos alunos, em grande parte, por simular o ambiente de sala de aula com a possibilidade de uso de vários recursos didáticos.

$\mathrm{Na}$ avaliação das ferramentas feita pelos professores, no que diz respeito à facilitação na compreensão dos conteúdos, o fórum foi apontado com 86,36\%, por 19 professores; seguido pela webconferência com 77,27\%, por 17 professores; o e-mail com 63,63\%, por 14 professores; e o chat com 54,53\%, por 12 professores, como mostra a tabela 2 .

Da mesma forma que os alunos, os professores também justificaram, por meio de uma questão discursiva, a avaliação feita em relação às ferramentas do AVA. O fórum foi considerado como muito eficaz, porque a dúvida postada por um aluno pode ser a dúvida de outros e, assim, forma-se uma lista de tópicos de dúvidas e esclarecimentos, gerando uma maior interação entre alunos e tutores a distância, o que colabora para o conhecimento de todos. Apontaram ainda que, quanto maior o número de participantes utilizando a ferramenta, mais eficaz ela se torna.

Como menos eficaz, os professores concordaram com os alunos apontando o chat, pois este necessita que todos os alunos estejam on-line em um horário determinado pelo tutor a distância ou pelo professor conteudista, o que causa incompatibilidade de horários entre os envolvidos.

Tabela 2 - Avaliação dos professores sobre os recursos interativos e visuais do AVA.

\begin{tabular}{|c|c|c|c|c|c|c|c|c|c|c|c|c|}
\hline \multirow{3}{*}{$\begin{array}{c}\text { FERRAMENTAS DO } \\
\text { AVA }\end{array}$} & \multicolumn{12}{|c|}{ NOTA ATRIBUIIDA } \\
\hline & \multicolumn{2}{|c|}{ Ineficaz (1) } & \multicolumn{2}{|c|}{$\begin{array}{c}\text { Pouco } \\
\text { eficaz (2) }\end{array}$} & \multicolumn{2}{|c|}{$\begin{array}{c}\text { Regularmente } \\
\text { eficaz (3) }\end{array}$} & \multicolumn{2}{|c|}{ Eficaz (4) } & \multicolumn{2}{|c|}{$\begin{array}{c}\text { Muito } \\
\text { eficaz (5) }\end{array}$} & \multicolumn{2}{|c|}{ Total } \\
\hline & $\mathbf{F}$ & $\%$ & $\mathbf{F}$ & $\%$ & $\mathbf{F}$ & $\%$ & $\mathbf{F}$ & $\%$ & $\bar{F}$ & $\%$ & $\mathbf{F}$ & $\%$ \\
\hline
\end{tabular}




\begin{tabular}{l|c|c|c|c|c|c|c|c|c|c|c|c}
\hline Chat & 1 & 4,6 & 2 & 9,1 & 7 & 31,8 & 9 & 40,9 & 3 & 13,6 & 22 & 100 \\
Fórum & 0 & 0 & 0 & 0 & 3 & 13,6 & 8 & 36,4 & 11 & 50 & 22 & 100 \\
E-mail & 0 & 0 & 2 & 9,1 & 6 & 27,3 & 9 & 40,9 & 5 & 22,7 & 22 & 100 \\
Videoaula & 0 & 0 & 2 & 9,1 & 3 & 13,6 & 10 & 45,5 & 7 & 31,8 & 22 & 100 \\
Webconferência & 0 & 0 & 1 & 4,6 & 4 & 18,2 & 7 & 31,8 & 10 & 45,5 & 22 & 100 \\
& & & & & & & & & & & & \\
\hline
\end{tabular}

Como observamos, no que diz respeito à eficácia dos recursos interativos e visuais disponibilizados no AVA como facilitadores na compreensão dos conteúdos, houve convergência de opinião entre professores e alunos.

Por meio das análises, percebe-se a necessidade e importância de uma maior proximidade e interação entre professor e aluno. As justificativas dos alunos a respeito da eficácia das videoaulas na compreensão dos conteúdos refletem a dependência da figura do professor em seu aprendizado, "[...] simula uma sala de aula". Em relação a esse aspecto, Lévy (1999) reforça que, em meio às tecnologias cibernéticas, o professor deve se comportar como um "animador da inteligência coletiva" que, por meio da troca de conhecimento, beneficie tanto o aprendizado individual quanto o aprendizado coletivo.

Conforme já falado no referencial teórico, a interatividade por meio das ferramentas midiáticas tem sido uma das grandes propostas da EaD para se construir o conhecimento individual e coletivo a partir dos conhecimentos preexistentes de cada sujeito envolvido no processo. Por conseguinte, perguntou-se aos alunos se as ferramentas disponibilizadas no AVA oferecem condições favoráveis para que o professor relacione o novo conteúdo àquilo que ele já sabe. Do grupo de entrevistados, 9 alunos (56\%) responderam que "às vezes" elas oferecem condições para tal, 5 alunos (31\%) responderam "sim" e uma minoria de 2 alunos (13\%) responderam que as ferramentas "não" oferecem condições favoráveis para que o professor relacione o novo conteúdo àquilo que eles já sabem conforme mostra a tabela 3.

Tabela 3 - Percepção dos alunos em relação às condições favoráveis das ferramentas do AVA à aprendizagem significativa.

\footnotetext{
As ferramentas disponibilizadas no AVA são favoráveis para que o professor relacione o novo conteúdo àquilo que o aluno já sabe?
}

\section{Opinião dos alunos}




\begin{tabular}{l|cc}
\cline { 2 - 3 } & F & $\%$ \\
\hline Sim & 9 & 56 \\
Não & 5 & 31 \\
Às vezes & 2 & 13 \\
TOTAL & 16 & 100 \\
\hline
\end{tabular}

O curso de Licenciatura em Informática dispõe aos professores formadores (professor conteudista/especialista, tutor a distância e tutor presencial) as seguintes ferramentas de comunicação: fórum de dúvidas, e-mail, webconferência, chat, telefone e também alguns encontros presenciais que, conforme citado no Projeto Pedagógico do Curso (PPC):

objetivam a análise e a reflexão dos trabalhos desenvolvidos em busca do direcionamento ou redirecionamento da ação (Teixeira,2010).

Como citado em Teixeira (2010), a relação do professor conteudista/especialista com os tutores presenciais será realizada de forma indireta intermediada pelo tutor a distância e por webconferência. Já a relação com os tutores a distância será direta, presencial por meio de encontros e por momentos virtuais.

Perguntou-se aos professores formadores como é feita a mediação entre eles, no que diz respeito aos conteúdos direcionados aos alunos, bem como às dúvidas dos mesmos. De acordo com as respostas dos professores, todas as ferramentas são utilizadas, sendo o fórum (26\%) e o e-mail (25\%) os mais usados, e o telefone $(6,25 \%)$ o menos usado conforme mostra a figura 1 . 


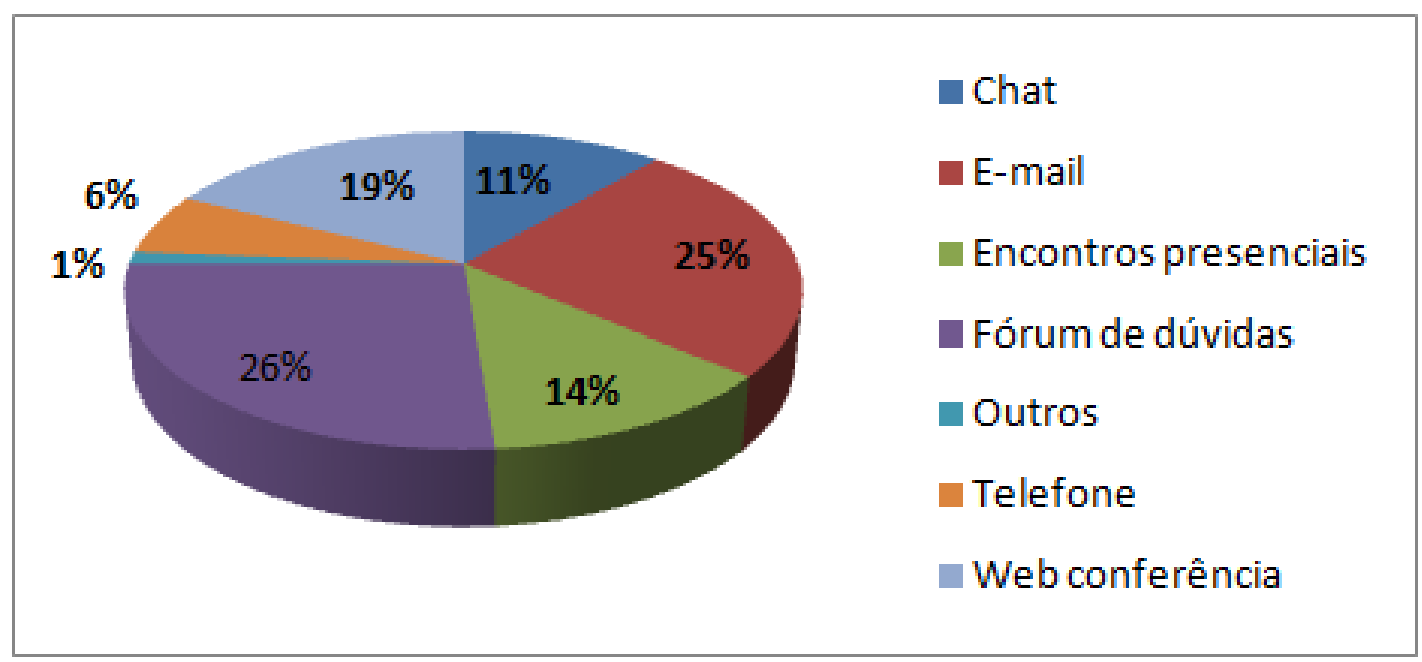

Figura 1 - Formas de mediação entre professores formadores.

De acordo com as respostas dos alunos, a mediação dos professores (conteudistas e tutores a distância) é feita através dos seguintes recursos: fórum, email, chat. O fórum é o recurso mais utilizado pelo professor conteudista ( $50 \%$ das respostas). O tutor a distância utiliza, na mesma proporção, o fórum e o e-mail, ambos com $42 \%$ das respostas. Cerca de aproximadamente $16 \%$ das respostas apontaram 0 chat como a ferramenta menos utilizada pelos professores conteudistas e tutores a distância com o aluno, possivelmente, pelos mesmos motivos considerados pelos pesquisados quanto a sua eficácia na compreensão dos conteúdos conforme mostra a Figura 2. 


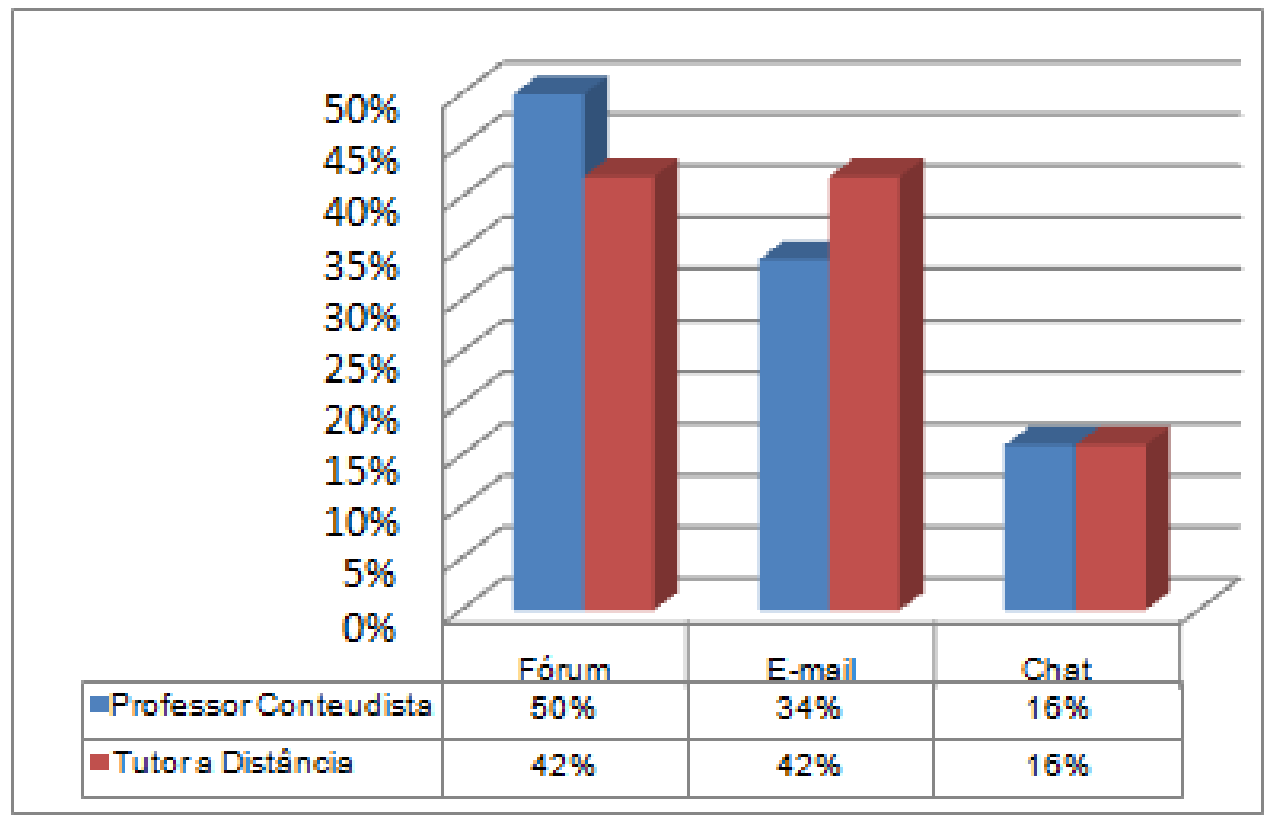

Figura 2 - Forma de mediação entre professores formadores e alunos.

Ainda mantendo-se no foco da interação entre educador e educando, perguntouse aos professores se a comunicação dentro do AVA tem atendido às necessidades imediatas de compreensão dos alunos. Do grupo, 10 professores $(45,5 \%)$ responderam "sim"; oito professores (31,85\%) disseram que "às vezes" conseguem atender a essas necessidades, e quatro professores $(18,2 \%)$ responderam "não".

Em relação a esse aspecto, a opinião dos alunos apresenta-se semelhante a dos professores. Do grupo, sete alunos (44\%) disseram "sim", que a comunicação dentro do AVA tem atendido às suas necessidades de compreensão, seis alunos (38\%) responderam "às vezes" e três alunos (18\%) disseram "não" conforme mostra a tabela 4.

Tabela 4 - Comunicação entre professor e aluno no AVA, quanto a compreensão dos conteúdos.

\begin{tabular}{l|cc|cc}
\hline $\begin{array}{c}\text { A comunicação dentro do } \\
\text { AVA tem atendido as } \\
\text { necessidades imediatas } \\
\text { de compreensão do } \\
\text { aluno? }\end{array}$ & \multicolumn{2}{c|}{$\begin{array}{c}\text { Opinião } \\
\text { dos alunos }\end{array}$} & \multicolumn{2}{c}{$\begin{array}{c}\text { Opinião } \\
\text { dos professores }\end{array}$} \\
\cline { 2 - 5 } Sim & F & $\%$ & F & $\%$ \\
Não & 7 & 44 & 10 & 45,5 \\
Às vezes & 3 & 18 & 4 & 18,2 \\
TOTAL & 6 & 38 & 8 & 36,3 \\
\hline
\end{tabular}


Ao comparar as respostas dos alunos que estavam cursando sua primeira graduação no curso de Licenciatura em Informática com a dos alunos que já possuíam graduação anterior, observou-se que, no primeiro grupo (alunos sem graduação anterior), cerca de cinco alunos (56\%) mostraram-se mais favoráveis no que diz respeito à comunicação dentro do AVA para a compreensão dos conteúdos em relação às respostas de dois alunos (29\%) que já possuem graduação conforme mostra a tabela 5 .

Tabela 5 - Comunicação entre professor e aluno no AVA na compreensão dos conteúdos na percepção de alunos com graduação e alunos sem graduação

\begin{tabular}{|c|c|c|c|c|}
\hline \multirow{2}{*}{$\begin{array}{c}\text { A comunicação dentro do } \\
\text { AVA tem atendido às } \\
\text { necessidades imediatas } \\
\text { de compreensão do } \\
\text { aluno? }\end{array}$} & \multicolumn{2}{|c|}{$\begin{array}{c}\text { Opinião dos alunos com } \\
\text { graduação }\end{array}$} & \multicolumn{2}{|c|}{$\begin{array}{c}\text { Opinião dos alunos sem } \\
\text { graduação }\end{array}$} \\
\hline & $\mathbf{F}$ & $\%$ & $\mathbf{F}$ & $\%$ \\
\hline Sim & 2 & 29 & 5 & 56 \\
\hline Não & 0 & 0 & 3 & 33 \\
\hline Às vezes & 5 & 71 & 1 & 11 \\
\hline TOTAL & 7 & 100 & 9 & 100 \\
\hline
\end{tabular}

Esse resultado pode estar relacionado ao fato de que os alunos com graduação geralmente são professores licenciados em áreas diversas, muitas vezes não relacionadas com tecnologia, o que pode ocasionar uma maior dificuldade no manuseio das ferramentas do ambiente.

\section{Considerações finais}

Quanto aos recursos disponibilizados no AVA, alunos e professores concordam que, se usados de forma adequada, são bastante eficazes na facilitação do aprendizado e na compreensão dos conteúdos. Apesar de o chat e de a webconferência serem consideradas as ferramentas síncronas que mais proporcionam a interação imediata 
entre professores e alunos, a videoaula foi considerada a ferramenta mais eficaz para a compreensão dos conteúdos, tendo em vista que esta fica disponibilizada no AVA e eles podem assistir a ela quantas vezes quiserem, e no horário que lhes convier, além de aumentarem a proximidade entre professor e aluno.

Este trabalho teve por objetivo fazer uma análise em relação ao uso das ferramentas interativas do Moodle no que tange a propiciar a aprendizagem significativa dos alunos.

Com esse intuito, acreditamos que os resultados deste estudo irão contribuir para melhorias na estrutura pedagógica do curso de Licenciatura em Informática e outros na modalidade a distância e, especialmente, na prática docente dos professores formadores que atuam ou que pretendem atuar em cursos ofertados na modalidade EaD.

\section{Referências bibliográficas}

Ausubel, D.P; Novak,J.D, Hanesian, H.( 1978). Educational psychology: a cognitive view. 2ed. Holt, Rinehart \& Winston.

Baldo, Yvina et al.(2008) O Modelo de Planejamento para o Desenvolvimento De Curso a Distância, Em: Anais CIAED, São Paulo. Disponível em: http://www.abed.org.br/congresso2008/tc/55200850729PM.pdf

Lévy, P. (1999) Cibercultura, Rio de Janeiro: Editora 34.

Machado, D. I.; Santos, P. L. V. A. da C. (2004). Avaliação da hipermídia no processo de ensino e aprendizagem da física: o caso da gravitação. In: Ciência \& Educação, v. 10, n. 1, (pp. 75-10). Disponível em: http://www.scielo.br/pdf/ciedu/v10n1/06.pdf

Minayo, Maria Cecilia de S; Sanches, Odécio.(1993) Quantitativo-Qualitativo: oposição ou complementaridade? Cad. Saúde Pública, Rio de Janeiro, 9 (3): (pp 239-262), jul/set. Disponível em:

http://unisc.br/portal/upload/com arquivo/quantitavivo qualitativo oposicao ou complementariedade.pdf

Moodle.org (s/d). Sítio Web de apoio à plataforma Moodle, acesso em 06 de Outubro de 2014. Disponível em: http://docs.moodle.org/en/About Moodle 
Silva Cinthia Lopes da; Velozo, Emerson Luís; RODRIGUES JR, José Carlos.(2008) Pesquisa qualitativa em Educação Física: possibilidades de construção de conhecimento a partir do referencial cultural. educ. rev. [online]. n.48, (pp. 3760). Disponível em: http://www.scielo.br/scielo.php?pid=s0102$\underline{46982008000200003 \& \text { script }=\text { sci } \text { arttext }}$

SBC - Sociedade Brasileira de Computação (2002). Currículo Referência para Cursos de Licenciatura em Computação. Em: Grupo de Trabalho de Licenciatura em Computação, Florianópolis.

Teixeira, Giovany. et al. (2010), Um Modelo para Gestão de Licenciaturas no EAD: Experiência do curso de Licenciatura em Informática - IFES, São Paulo, Em: Anais CIAED. Disponível em: http://www.abed.org.br/congresso2010/cd/2732010101024.pdf

Tonelli, E. ; DEPS, V. L. ; Souza, C. H. M. ; Manhaes, F. C. (2014). A aprendizagem significativa no ambiente virtual de aprendizagem: um estudo na percepção de alunos e professores na educação a distância. RIALAIM, v. 3, (pp. 49-58). Disponível

em: http://soda.ustadistancia.edu.co/enlinea/paginaimagenes/congreso/MemoriasXI Congreso/elliz\%20tonelli.pdf 